\title{
Study on the Development of Water Transport Network for Passengers in the Gulshan-Banani-HatirJheel Lake of the Capital City of Bangladesh
}

\author{
Md. Mashiur Rahaman, Mir Tareque Ali and Laboni Afroz \\ Department of Naval Architecture and Marine Engineering, Bangladesh University of Engineering and Technology, Dhaka-1000, \\ Bangladesh
}

\begin{abstract}
Dhaka, the capital city of Bangladesh is one of the most overpopulated city in the world and traffic jam is the most severe and regular affliction in the daily life. Also, the existing vehicles are not sufficient in compared to the population of the city. People have to spend many hours simply sitting in the traffic jam. This lessens the productivity of people and brings sufferings to them. Gulshan-Banani-HatirJheel area is the busiest regions within the city and face severe traffic jam during working hours. These lakes are totally unused. Therefore, there is a possibility to build a waterways network for passengers transport through these lakes. This will reduce the affliction of people via reducing traffic jam. The proposed transportation networks will also preserve the natural environment of the lakes and bring a source of entertainment in the city life. Many developed cities in the world like London, New York, Paris, Venice, Shanghai etc. already have implemented waterways network inside the city and successfully made the best use of cistern side.
\end{abstract}

Key words: Water transport, network, passengers, Gulshan-Banani-HatirJheel Lake.

\section{Introduction}

With Bangladesh's huge population and current infrastructure, frequent traffic jams waste valuable fuel and time and makes travel very unpleasant and difficult. Furthermore, it makes the existing public transport very inefficient and most importantly adds unbearable and unsafe levels of noise and hazardous air pollution. The noise levels and pollution cause stress in the most people and lead to many life-threatening medical conditions such as cardiovascular diseases and blood pressure related ailments.

With continued economic growth and development, Dhaka, the capital of Bangladesh is beginning to experience massive traffic congestion. Today, this is causing extreme frustration to the inhabitants of the metropolitan which is the largest and most crowded

Corresponding author: Md. Mashiur Rahaman, Ph.D., research fields: computational fluid dynamics (CFD), port and harbor engineering, dredger and dredging technology, ship recycling. Email: mashiurrahaman@name.buet.ac.bd. city of the nation. Many government and public transport agencies drafted policies, undertook projects and implemented programs to solve these problems. For example, the Dhaka Integrated Transport Studies conducted by the Ministry of Planning in 1991-1994 found that not only did the uncoordinated activities of DCC (Dhaka City Corporation), RAJUK (Rajdhani Unnayan Kartripakkha) and BRTA (Bangladesh Road Transport Authority) not yield the desired effects or alleviate the problems but also that there was no single organization responsible for improving the transport and traffic problems of the city.

With financial assistance from the World Bank, in 1998, Bangladesh Government created the Dhaka Transport Coordination Board. An urban transport plan was commissioned with the US Consulting Group Louis Berger and BCL (Bangladesh Consultant Ltd). The plan, launched in 2008, laid out a comprehensive transport plan for the Greater Dhaka City and its adjoining areas, such as Tongi, Gazipur, Savar, 
Narayanganj, Keraniganj, Narshingdi and Manikganj, covering around 1,530 square miles. The plan looked at 15 Key Policy issues including safety, pedestrian preferences, public transport, non-motorized transport, travel demand management, mass transit systems, etc. Almost 70 different policy recommendations were produced under these 15 issue areas. Ten comprehensive transportation strategies were then evaluated, using a base case of no BRT (Bus Rapid Transit) or metro service and exploring many alternative combinations [3]. Finally the adopted plan included roads in addition to using a 3 Line MRT (Mass Rapid Transit) and the 3 Line BRT. Furthermore, the plan included provisions for 54 new roads in and around the city, 3 parts elevated expressways and a circular waterways program.

But with the increasing population, all the steps failed to reduce traffic jam. It's the right time to think differently. There are some cisterns within the city. If steps are made to develop waterway using these cisterns, it will help greatly in reducing the traffic jam in the city and related affiliations. There is a two large intra connected lakes in Gulshan and Banani where development of a waterway is quite possible.

\section{Location and Particulars of Gulshan-Banani}

Gulshan and Banani lakes (shown in Fig. 2) are located $23^{\circ} 48^{\prime} \mathrm{N}$ and $90^{\circ} 25^{\prime} \mathrm{E}$ of Dhaka city [4]. According to Refs. [5, 6] length of Gulshan Lake is
$3.89 \mathrm{~km}$. Width varies from point to point. The lake is wider on the south. Maximum width is $203.51 \mathrm{~m}$ and minimum width is $64.04 \mathrm{~m}$. Mean depth is $2.50 \mathrm{~m}$. The total estimated area is around 145.48 acres. On the other hand, Banani Lake has a length of $3.43 \mathrm{~km}$. Width of the lake is maximum $116.54 \mathrm{~m}$ and minimum $21.89 \mathrm{~m}$. Mean depth is $2.0 \mathrm{~m}$ [7]. It has an area of 80.81 acres.

\subsection{Present Conditions of the Lakes}

Gulshan-Banani-HatirJheel Lake area remains almost unused throughout the year. There are housings on the both sides of these lakes and a slum near the Banani Lake. Gulshan Lake and its surroundings continue to be polluted as household wastes and sewage find their way into the water body. With the city experiencing development every day, its water bodies are shrinking and the Gulshan Lake is the best example of how the negligence of the authorities concerned leads to the wretched condition of a water body. People who have walks beside the lake have to bear the bad smell and step over rubbishes littered on the walkways.

Visiting the Gulshan-Banani Lake area it was found that many illegal encroachments were still intact around the lake. Only a small area of the lake had been filled up for building a $2.5 \mathrm{~km}$ driveway along the eastern side, starting behind Gulshan Shooting Club and ending at Mariam Tower just behind the United States of America embassy. Sewerage pipe lines were

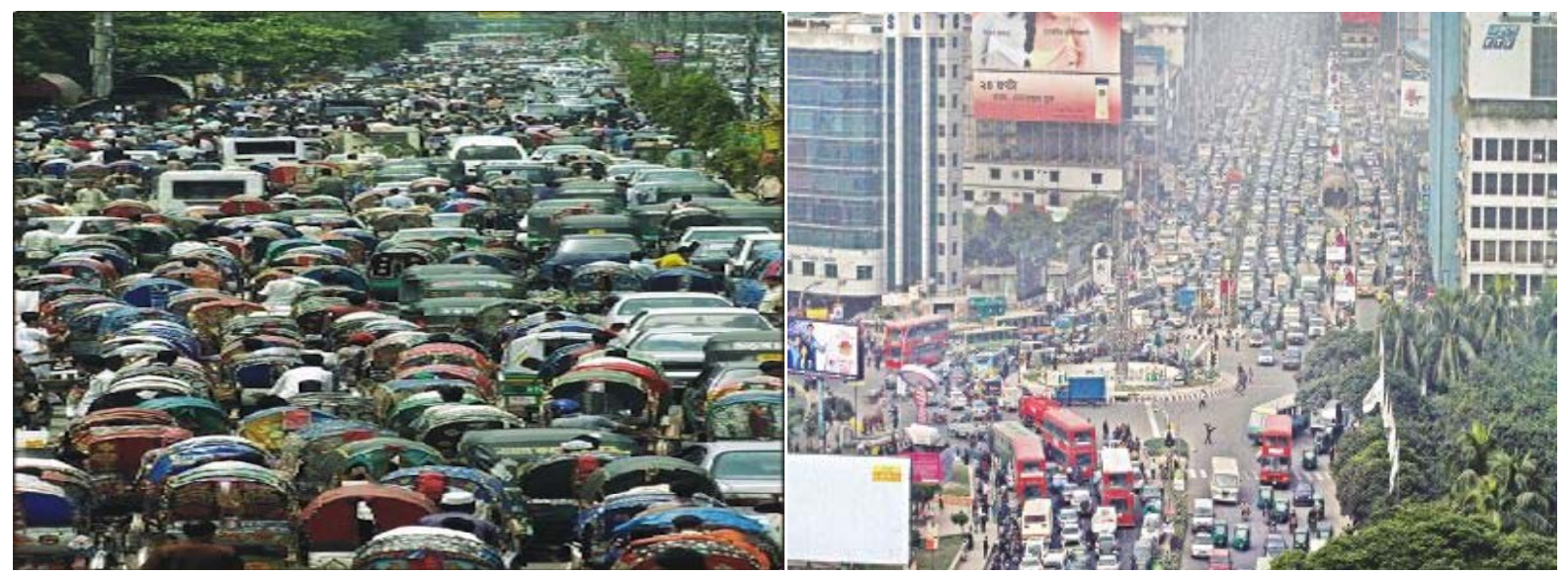

Fig. 1 Traffic jams in the streets of Dhaka metropolitan area [1, 2] 


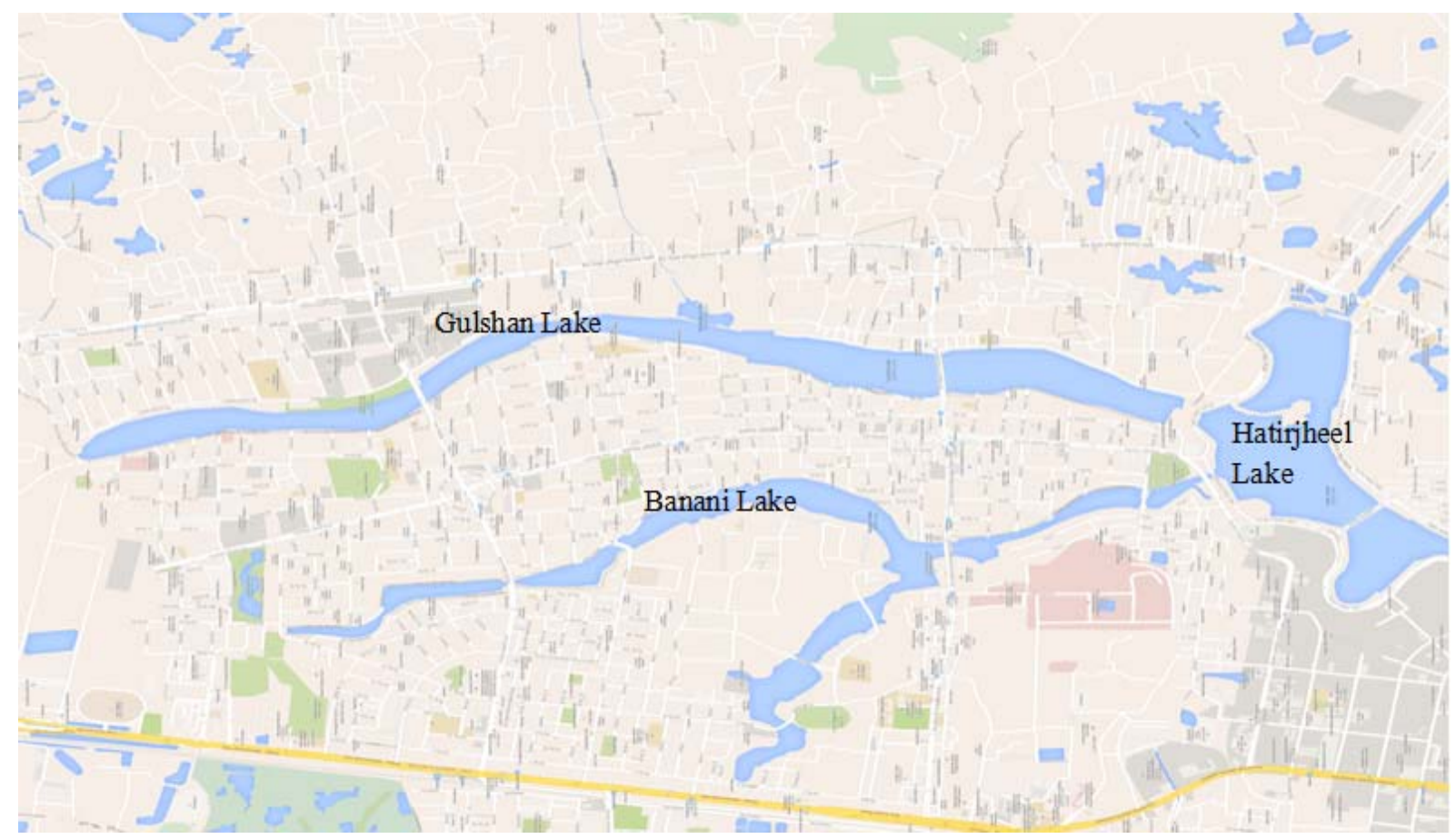

Fig. 2 Location of Gulshan-Bananai-HatirJheel Lake [8]

Table 1 Estimation of number of public transports in the busiest hours

\begin{tabular}{lll}
\hline Duration of survey & Number of public transports \\
\hline Gulshan to HatirJheel & \\
\hline \multirow{2}{*}{ March 10, 2015} & $09.00 \mathrm{am}-10.00 \mathrm{am}$ & 181 \\
& $10.00 \mathrm{am}-11.00 \mathrm{am}$ & 165 \\
\hline Banani to HatirJheel & $11.00 \mathrm{am}-12.00 \mathrm{pm}$ & 151 \\
\hline & & 132 \\
February 18, 2015 & $11.00 \mathrm{am}-12.00 \mathrm{pm}$ & 121 \\
& $12.00 \mathrm{pm}-01.00 \mathrm{pm}$ & $\mathbf{7 5 0}$ \\
\hline
\end{tabular}

found discharging sewerage into the lake.

\subsection{Traffic Scenario of Gulshan-Banani-HatirJheel Area}

Gulshan, Banani, HatirJheel are the busiest regions in Dhaka Metropolitan area. Severe traffic jam is a regular scenario in these regions. Usually, it should take about 30-40 minutes to travel from Gulshan to HatirJheel and Banani to HatirJheel. But during working day due to severe traffic jam, it takes 1.5-2 hours to cover the above-mentioned distance. As a result valuable times and energy are being wasted, which makes less efficiency in the various activities of the people who use that route.

\subsection{Present Scenario of Public Transports}

For the estimation of passengers traveling these areas, the busiest traveling time is considered as 8.00 am to $10.00 \mathrm{pm}$. That means twelve busiest hours are taken into consideration. Public buses can carry about 40 nos. passengers in average. But all the passengers may not travel from Gulshan to HatirJheel or Banani to HatirJheel. As the areas that are considering cover only about three to four $\mathrm{km}$, it is considered in present analysis that less than $30 \%$ passengers travel for the region concerned. A survey was conducted by the present authors on February 18, 2015 at Banani and March 10, 2015 at Badda to estimate the number of 
passengers traveling through public transports. The results of the survey are furnished in Table 1.

So, the total no. of passengers traveling per day in the Gulshan to HatirJheel and Banani to HatirJheelregion is about 21,000 nos.

\subsection{Travel Costs Needed at Present}

Gulshan and Banani lakes are connected in HatirJheel area. Banani Lake has a branch leading to Dhaka-Mymensingh highway near Chairman Bari. There are five bridges and two damns on the way of lakes. These damns prevent the free flow of water. Observation was made on these damns and bridges. The bridges have no enough air draft for boats to pass. These should be destructed and new bridges are to be constructed in order to develop a waterway. In north, Gulshan Lake starts from United Hospital ends at HatirJheel. On the other way, Banani Lake starts from Banani Catholic Church and ends at HatirJheel and connected with the Gulshan Lake there. There are two common roads passing through these lakes.

When using road transport from PragatiSarani to HatirJheel area, the distance is about $4.5 \mathrm{~km}$. There are two types of public buses: counter sitting service and local bus. For traveling through counter sitting service, the waiting time is around 10 to 20 minutes as buses are less than the required. It takes around 40 minutes to 1 hour to cover the destination.

Road distance from Banani to HatirJheel is about $3.07 \mathrm{~km}$. It takes about 1 hour for a counter bus service and 1.5 hours for a local bus service. The traveling costs for this area are shown in Table 2.

\section{Physical Constraints Associated with Development of Water Transport Network}

For the development of waterways, some physical constraints as dams and bridges, polluted water, bends and depth are associated and by taking steps, these can be overcome easily.

Some bridges and dams are constructed across the lake for road transport. At present, existing bridges have not high enough to provide air draft for the shallow draft boat. Therefore, these bridges and dams are necessary to be re-constructed. By physical survey, it is found that there are three bridges and a dam in Gulshan Lake. Banani Lake contains four bridges of which all of them needed to be re-constructed. However, one newly built bridge near to HatirJheel has not enough air draft, which also needs not to be rebuilt.

The water of the lake is severely polluted and full of odor. This is an obstacle for the passengers to travel through shallow water boat. Therefore, water purification plant has to be developed. At least, two water purification plants should be built to purify the odorous of water for Gulshan and Banani Lake. Some regions of the lakes are very narrow. There are also rapid changes of direction of the lakes.

In present analysis, points are identified in the lakes (in Fig. 3) to show the variation of the width and position of the existing bridges and damns. In the Table 3 , the location of points and their corresponding width and locations of bridges and dams are mentioned.

\section{Design Criteria for Suitable Boat Design}

The main objective of the present study is to design a waterway that will lead to a saving of time and money along with lessening the affliction related to the traffic jam. Therefore, an optimum shallow water draft boat is necessary for the proposed waterways network. Also due to physical constraints in the lake i.e. width and draft of the lake, bends etc. leads the necessity of a boat with moderate speed and size. Special attention should

Table 2 Traveling cost for road transport

\begin{tabular}{ll}
\hline Route and services & $\begin{array}{l}\text { Cost in BDT } \\
(1 \mathrm{BDT}=0.0129 \text { USD })\end{array}$ \\
\hline Gulshan to HatirJheel & \\
\hline Counter bus service & 25 \\
Local bus service & 10 \\
Human pulled Rickshaw & $70-80$ \\
\hline Banani to HatirJheel & \\
\hline Counter bus service & 35 \\
Local bus service & 15 \\
Human pulled Rickshaw & $120-150$ \\
\hline
\end{tabular}


Study on the Development of Water Transport Network for Passengers in the

Gulshan-Banani-HatirJheel Lake of the Capital City of Bangladesh

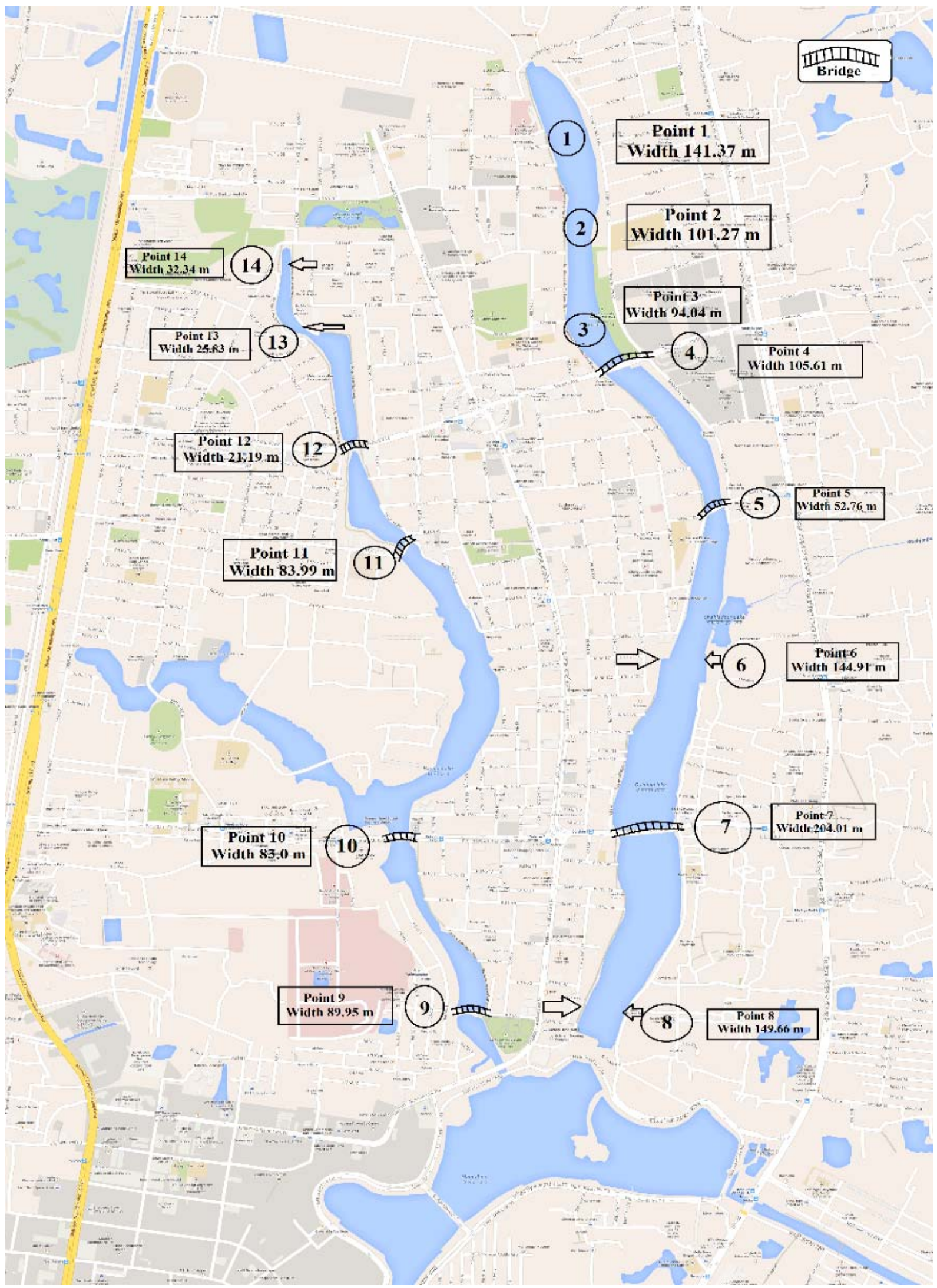

Fig. 3 Width of the lakes at different points and position of bridges and dams 
Table 3 Location of various points showing their width.

\begin{tabular}{lll}
\hline Point & Location & Width (meter) \\
\hline Point 1 & Road no. 8 & 141.37 \\
Point 2 & Road no. 5 & 101.27 \\
Point 3 & Road no. 3 & 94.04 \\
Point4 & Madani avenue & 105.61 \\
Point 5 & Road no. 106 & 52.96 \\
Point 6 & Road no. 123 & 144.91 \\
Point 7 & A K Khandakar Road & 204.01 \\
Point 8 & Sattar Bhuyan Res & 149.66 \\
Point 9 & Road no. 1 & 89.95 \\
Point 10 & A K Khandakar Road & 83.0 \\
Point 11 & Banani bridge & 83.99 \\
Point 12 & Kamal Ataturk Avenue & 23.19 \\
Point 13 & Road no. 20 & 26.83 \\
Point 14 & Road no. 18 & 32.34 \\
\hline
\end{tabular}

be taken so that the operation of the boat will not be a reason for pollution of the lakes. Again, as there are residential buildings beside the lakes, the boat should not be a source of noise.

\subsection{Physical Restrictions for Operation of Boat}

To design a boat, the following restrictions are identified, which need to be considered for designing the boat.

- The minimum breadth of one of the lake is $24.0 \mathrm{~m}$.

- Time to travel through boat should be less than the time to travel through road transport

- Capacity of the boat should be such that the project will lead to a profit within a specified time.

- Traveling cost for boat should be less than the traveling cost for road transports.

- Turning circle of the boat should be such that it will not face any difficulty during turn through narrower zone.

\subsection{Required Operational Speed of Boat}

Since the travel time required by road transport in the proposed area is about 30 to 40 minutes without traffic jam and one hour to one and half hour with traffic jam, 20 minutes travel time is considered for travel by boat through the proposed waterways network. So, the speed of the boat will be,

$$
\begin{gathered}
\text { Shipspeed }=\frac{4000 \mathrm{~m}}{20 \times 60 \mathrm{~s}} \\
=3.33 \mathrm{~m} / \mathrm{s} \\
=\frac{3.33}{0.5144} \mathrm{knot} \\
=6.48 \mathrm{knot}
\end{gathered}
$$

Therefore, a boat with speed of $7.0-\mathrm{knot}$ is considered.

\subsection{Calculation of Principal Particulars of Boat}

Now for estimating the capacity and principal particulars of the boat, passenger seats are arranged in five rows. In each row, there will be four seats and a space equal to o199ne seat for walking. Breadth of each seat is $0.46 \mathrm{~m}$. Then five seats need $5 \times 0.46=2.30 \mathrm{~m}$ space. Therefore, breadth of the boat is taken as $2.50 \mathrm{~m}$. In each seat, $0.76 \mathrm{~m}$ space is required in longitudinal direction. Space for 5 rows is $3.80 \mathrm{~m}$, steering space = $2.0 \mathrm{~m}$ and space for engine is $1.5 \mathrm{~m}$. So, total space required in longitudinal direction is $7.30 \mathrm{~m}$. Therefore, the length of the ship is taken as $7.50 \mathrm{~m}$. Since the minimum depth of the lakes is $1.25 \mathrm{~m}$, draft is assumed as $0.80 \mathrm{~m}$. The principal particulars of the proposed boat are described in Table 4.

\subsection{General Arrangement of Boat}

Fig. 4 shows the profile plan of the boat which is designed for the proposed waterways network whereas Figs 5 and 6 show the seating arrangements and 3D view of the boat respectively.

\subsection{Freight Rate Calculation}

Capacity of the boat is 20 passengers. If freight rate is taken as BDT30 which is about $20 \%$ less than the cost of road transport, then the net income generation will be BDT 600. Also, the travel time required per trip will be about 20 minutes that leads a round trip per hour

Table 4 Principal particulars of boat

\begin{tabular}{lll}
\hline Particulars & Dimension & Unit \\
\hline Length & 7.50 & {$[\mathrm{~m}]$} \\
Breadth & 1.50 & {$[\mathrm{~m}]$} \\
Draft & 0.80 & {$[\mathrm{~m}]$} \\
\hline
\end{tabular}



Gulshan-Banani-HatirJheel Lake of the Capital City of Bangladesh

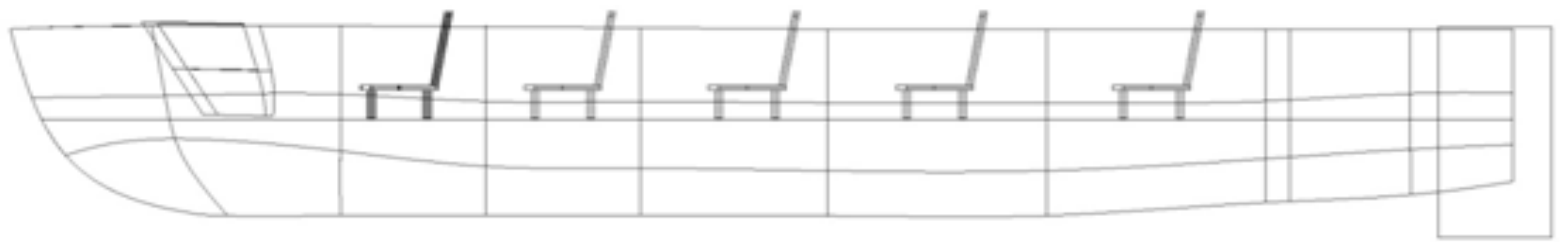

Fig. 4 Profile plan of boat

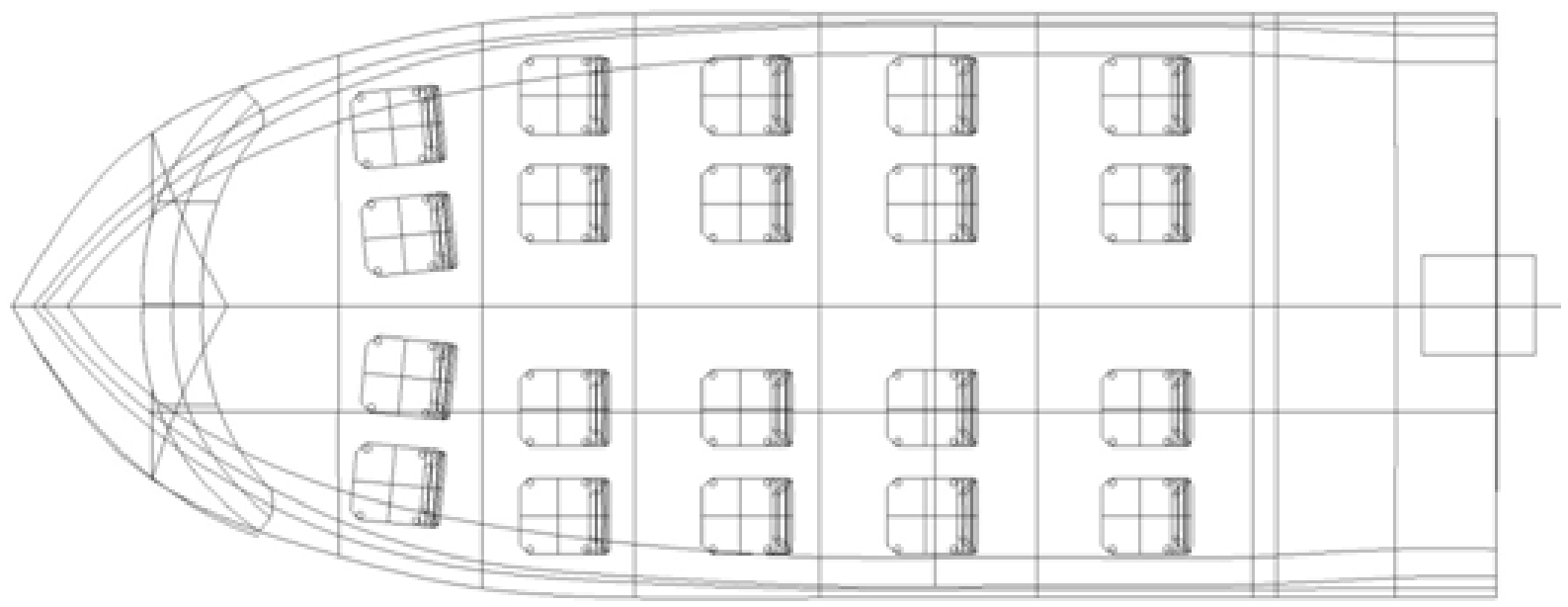

Fig. 5 Seating arrangement of boat

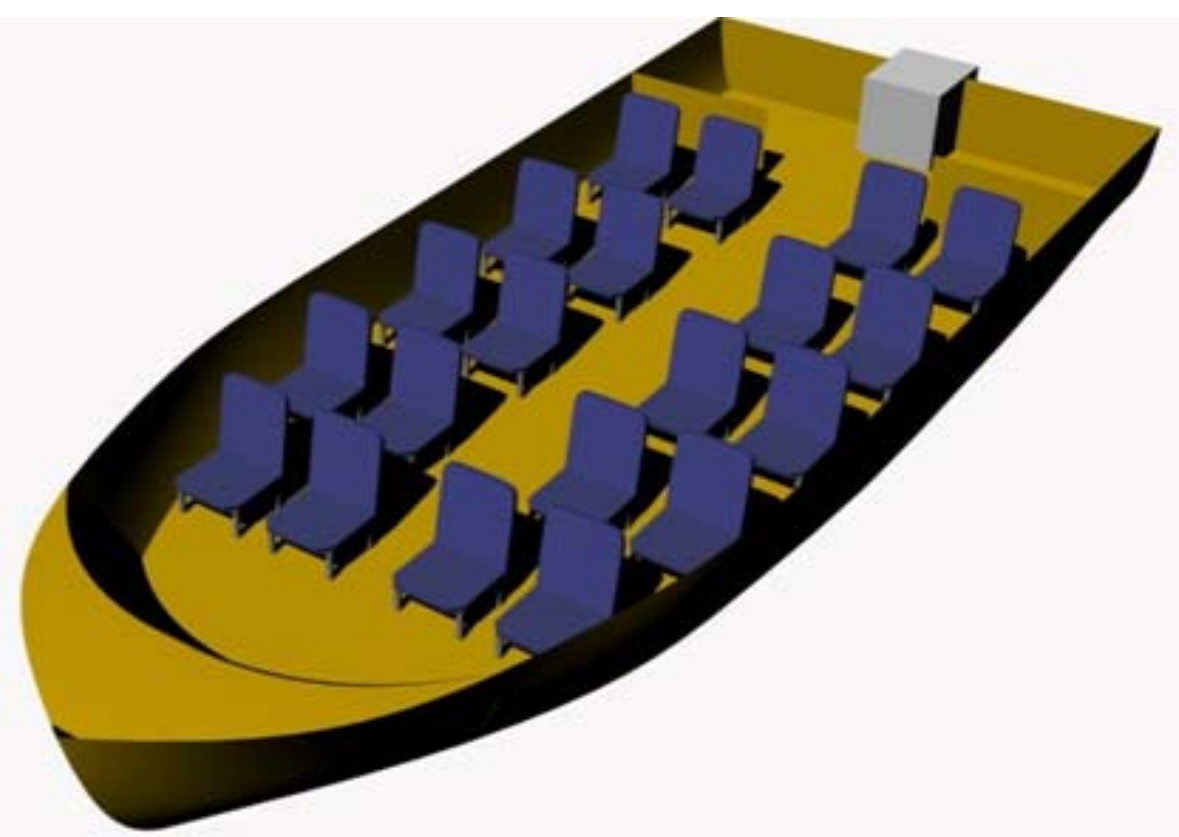

Fig. 6 3D view of the designed boat

by the boat.

\subsection{Initial Infrastructure Development Costs}

On the basis of the survey of the local market of Bangladesh, the required costs of materials for constructing new bridges and other facilities the total costs needed to implement the proposed waterways network will be about BDT 330 million. Average cost for construction of a boat is about BDT 2 million. Let us assume that there will be a total of 40 nos. boats in 
service, in which 20 nos. in Gulshan to HatirJheel waterway and 20 nos. in Banani to HatirJheel waterway.

Then total initial investment will be BDT 440 million. In present analysis, estimated no. of passengers for this route is 21,000 . If 40 nos. of boats are in service, then the total no. of trips per day will be 960 trips and will carry 19,200 nos. of passengers per day. If the freight rate is taken as BDT 30 , then the net income per day is BDT 0.15 million.

\section{Conclusion}

At present, the Government of Bangladesh has taken various initiatives to reduce the traffic jam in Dhaka city. But no initiative is successful yet. Therefore, implementation of waterways network for the proposed area inside the capital city can be a possible alternative and an excellent solution for reducing traffic jam. Also, by implementing the proposed networks, a suitable use of the unused lakes can be made, which will beautify the area and can be a good creation area for the people.

\section{References}

[1] http://emonhossain.hubpages.com/hub/Traffic-Jam-in-Dh aka-City.

[2] http"archive.thedailystar.net/newDesign/news-details.php ?nid=261853.

[3] https://en.wikipedia.org/wiki/Bus_rapid_transit.

[4] http://www.kaagoj.com/details?id=356.

[5] Roksana R., Khondokar M., and Islam, M. S. 2012. "Limnology of a Conserved Man-Made Lake in Bangladesh, I.Physical and Chemical Factors.” Dhaka University Journal of Biological Science (21): 131-40.

[6] Mohuya, F. A., Bhuiyan, R. H., and Hoque, S. 2010. "Heavy Metal Contamination in Gulshan-Baridhara Lake." Dhaka University Journal of Biological Science (19): 53-61.

[7] Detailed Area Plan (DAP) for Dhaka Metropolitan Development Plan (DMDP).

[8] Area plan of Gulshan-banani Lake Beautification Project by "Vitti Sthopotibrindo", http://www.dhakatribune.com/development/2013/nov/24/ gulshan-lake-development-bogged-down. 